\title{
NON-LINEAR STRAIN ANALYSIS OF COUPLED SUB-MARINE PIPELINES DURING THE LAUNCH PHASE
}

\author{
Minutolo V.*, Palladino S., Ferla P, Zona R., Esposito L. and Di Natale M. \\ Department of Engineering, University of Campania, "Luigi Vanvitelli", \\ via Roma, 81031 Aversa, Italy \\ *Corresponding Author E mail: vincenzo.minutolo@unicampania.it
}

\begin{abstract}
It is shown the deformation analysis, in large displacements hypothesis, for two coupled sub-marine pipes rigidly connected and launched at the same time. Hydrodynamic forces on the pipes are referred only to drag component for which the semi-empirical Morison equation is used. For the hydrodynamic coefficients the results of experimental tests, reported in literature are used. The analysis of deformation of the structure under the effects of hydrodynamic loads and axial forces is carried out within the Bernoulli's hypothesis of the conservation of plane cross sections, without any torsional and Von Karman ovalization effect. The equations of the problem were expressed as a function of the slope of the cross section. In order to solve these equations an appropriate numerical model is presented. Finally, some examples are reported in which the use of this method in practical application is shown as well as the advantage of launch of coupled pipes in respect of single ones.
\end{abstract}

Keywords: Pipeline, offshore structures, large displacement, hydrodynamic forces on pipelines, pipelines installation, pipeline laying, flexural beam method.

Cite this Article: Minutolo V., Palladino S., Ferla P, Zona R., Esposito L. and Di Natale M., Non-Linear Strain Analysis of Coupled Sub-Marine Pipelines During the Launch Phase. International Journal of Civil Engineering and Technology 11(1), 2020, pp.53-63.

https://iaeme.com/Home/issue/IJCIET?Volume=11\&Issue $=1$

\section{INTRODUCTION}

The discharge of wastewater into the sea, using submarine pipelines, is commonly adopted even in the presence of a treatment plant, because it improves the overall efficiency of the system, both under normal operating conditions and in the event of plant failures. When the area of the served basin becomes too large and the sewerage network is of mixed type, the flow rates to be discharged during a rainfall event require significant pipe diameters, until it is necessary to use more pipes in parallel. In this kind of situation, the pipelines' launching phase, carried out with the traditional criterion of pulling on the bottom, takes place through the laying of one-time pipeline. This causes some drawbacks that can turn into higher costs 
during the construction phase. In fact, during the launch phase, separate site installations are used for each pipeline, reducing installation times but increasing construction costs. Conversely, if a single installation is used, the overall launching time becomes equal to the sum of the time required for the laying of each pipeline. In this type of work, the role of the hydraulic risk associated to the swift changes in the sea climate is very important, which also in the second case would involve higher costs due to longer launch times. In the case of plastic pipes (lighter and more flexible than metal ones) it is important to point out that in the presence of even weak sea currents, it causes a lateral bending of the single pipe with strains that can give an incorrect installation or failure strength of the pipe. For the problems previously described, for a system with two pipes, a single construction site can be used on the ground, equipped for the simultaneous joining of two parallel pipe sections. They are connected by proper collars connected to spacers, which, making the two pipes integral, allows a single launching operation (Fig.1). The system previously mentioned, not only ensures shorter times and lower costs, but also allows to have a structural system that has a greater transversal stiffness compared to that composed of two separate pipes, giving an excellent resistance to sea flows with transversal impact.

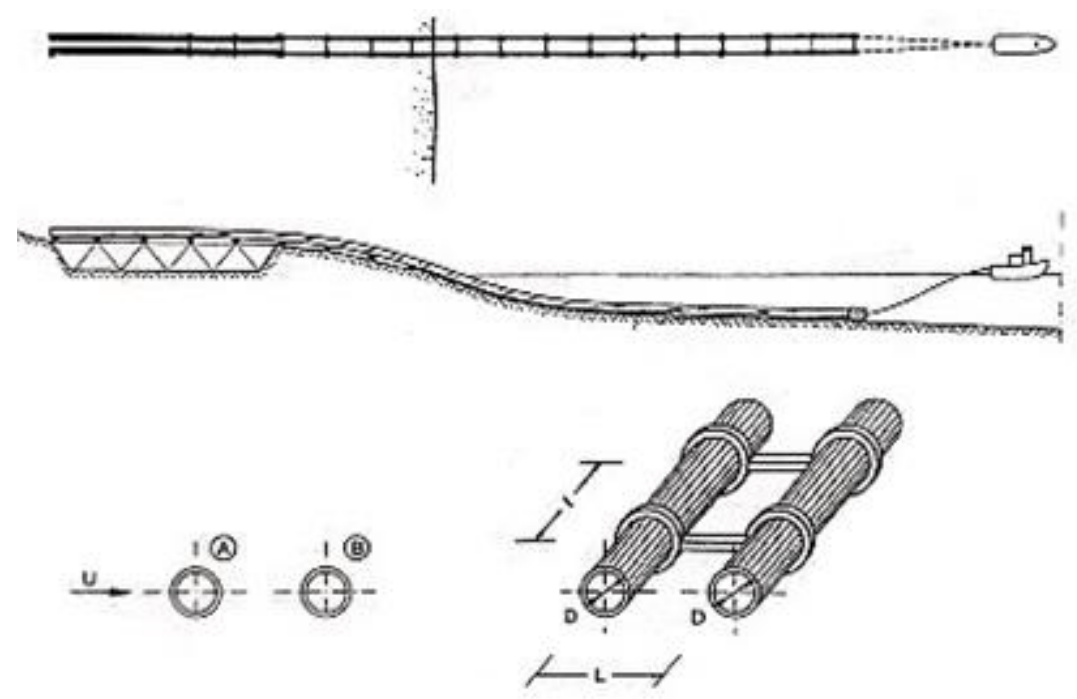

Figure 1 Scheme of coupled pipelines in a launching phase

First, to evaluate the efficiency of the coupled pipeline scheme it is necessary to evaluate the intensity of the transverse force, FD, linked to a current of prefixed speed $U$. Subsequently, the structure strain is determined as a function of the diameter D of the pipes, their thickness p, material elastic modulus E, transversal wheelbase L, collar longitudinal wheelbase 1, and end constraint conditions. A criterion for an approximate solution linked to the coupled sub-marine pipelines has been reported. The criterion has been based on a static analysis of the structure based on large displacements model using a scheme of deflected and constrained beam at the end side. The beam has been loaded with a lateral distributed uniform force, FD, and with an axial load, H, determined from the boat shooting. In order to evaluate FD, the Morison's semi-empiric relation has been used [1] supposing to have a real steadystate fluid. Moreover, linked to the static equilibrium in large displacements state, Bernoulli's scheme has been used [2,3].

The general equilibrium formulation of the flexure of straight beam element under the hypothesis of large displacements are proposed in the case of pipelines [2, 3, 4] starting from the Bernoulli's hypothesis. The formulation give rise to nonlinear ordinary differential equations that are solved through a numerical incremental strategy. The formulation starts from large deflection equations of the beam and considers the possibility of large curvatures 
in $[5,6,7,8,9]$. Many numerical application are reported in the literature, in [10] a numerical procedure is described that optimises the strategy of pipelines laying, in [11] a new method for support coupling of pipelines in the framework of generalised beam theory where local effects of supports is analysed considering the beam ovalization and warping. In [12] the Boundary element method is used in order to evaluate the pipeline behaviour during the installation stage. Many works deals with the numerical solution of the equilibrium equation of pipelines [13, 14].

The equations used in the paper, are simplified but they haven't an analytic form resolution, so the results have been researched in a numerical way. A practical example between coupled pipelines and single ones has been proposed. Therefore, some useful pictures for the structural parameters' definition have been reported.

\section{ANALYSIS OF HYDRODYNAMICS' FORCES}

In a general way, the hydrodynamics forces about an obstacle inside a kinematic fluid rate, has been proposed using two different schemes. The first one, represent a real steady-state fluid. Instead, the second one has been referred to a variable state of an ideal fluid [15] The stresses linked the two schemes previously introduced, must be considered valid only inside them. In the conditions of a steady-state and real fluid, it is clearly known the fact that a yield stratum around the pipeline is formed due to a separating phenomenon near the valley zone $[16,17]$ The speed gradients and the vortices system of the valley's trail involve on the pipeline surface a normal and shear stresses which are always hard problems into the hydrodynamics field. In the Morison's scheme [1], the resultant stress previously introduced, is decomposed into two components respectively. The first is named "drag force" and is directed along the direction of the pipe motion and representing the strength effect due to the limit strata. The second one, orthogonal to the first one and named "lift force" is linked to the transversal pressure gradients due to the asymmetrical distribution of flow lines. The analytic expressions for the FD and FL forces with reference to the single pipeline having a diameter D subjected to the constant speed $\mathrm{U}$ are:

$$
\begin{gathered}
F_{D}=0.5 C_{D} \rho D U|U| \\
F_{L}=0.5 C_{L} \rho D U^{2}
\end{gathered}
$$

In reference to the equations (1), $\rho$, is the density of the fluid while $C_{D}$ and $C_{L}$ represent two hydrodynamic coefficients whose nature is typically experimental. The estimation of these two coefficients depends on some dimensionless parameters, such as: the Reynolds number $R e=\frac{U D}{v}$, where, $v$ is the kinematic viscosity, the relative roughness of the pipeline $\cdot \frac{k}{D}$ and the geometrical ratio $\frac{e}{D}$, where e is the distance of the pipeline from the bottom of the sea. The typical values of $C_{D}$ and $C_{L}$ are reported in several experimental works $[18,19]$. The passage from the single pipeline scheme to the one under examination of two coupled pipelines $\mathrm{A}$ and $\mathrm{B}$ of diameter $\mathrm{D}$ at a distance $\mathrm{L}$, involves some hydrodynamic complications connected to the fact that the flow field that develops around the two pipelines is different from that related to a single pipeline. In fact, the forces acting on the pipeline A, directly exposed to the current, will be characterized by the interference of the fluid flow with the second pipeline $\mathrm{B}$, which will be subjected to a flow field different from the initial one at constant speed $\mathrm{U}$. The intensity of the interference produced is inversely proportional to the ratio $\frac{L}{D}$ between the distance of the two pipelines and their diameter. Such an effect becomes negligible for values of $\frac{L}{D}>50$. With reference to the current technical literature, the $F_{D A}$, $F_{L A}, F_{D B}, F_{L B}$ values on each pipeline, has been calculated through the relations (1), which 
accounts for the hydrodynamics coefficients values considering the interference between them.

For the first of these coefficients, in the technical literature, it's important to highlight the fact that for the values of $R e>10^{5}$, overriding mode, there haven't been reported enough experimental data, causing the non-applicability in practical cases. Conversely, for $\operatorname{Re}<10^{5}$, sub-critical mode, the value of $C_{D}$ can be obtained by means of experimental curves as a function of the ratio $\frac{L}{D}$ reported in fig.2 [20]. Notice the fact that for the pipeline A, the following limitation holds: $0.8<C_{D}<1.1$ for $1<\frac{L}{D}<3$ and $C_{D} \cong 0.8$, constant value, for $\frac{L}{D}>3$. In the case of the pipeline $\mathrm{B},-0.5<C_{D}<0.3$ for $1<\frac{L}{D}<3$ and $0.4<C_{D}<0.6$ for $\frac{L}{D}>3$ (Figure 2). ones.

In the present paper, lift forces have been considered negligible in respect to the drag

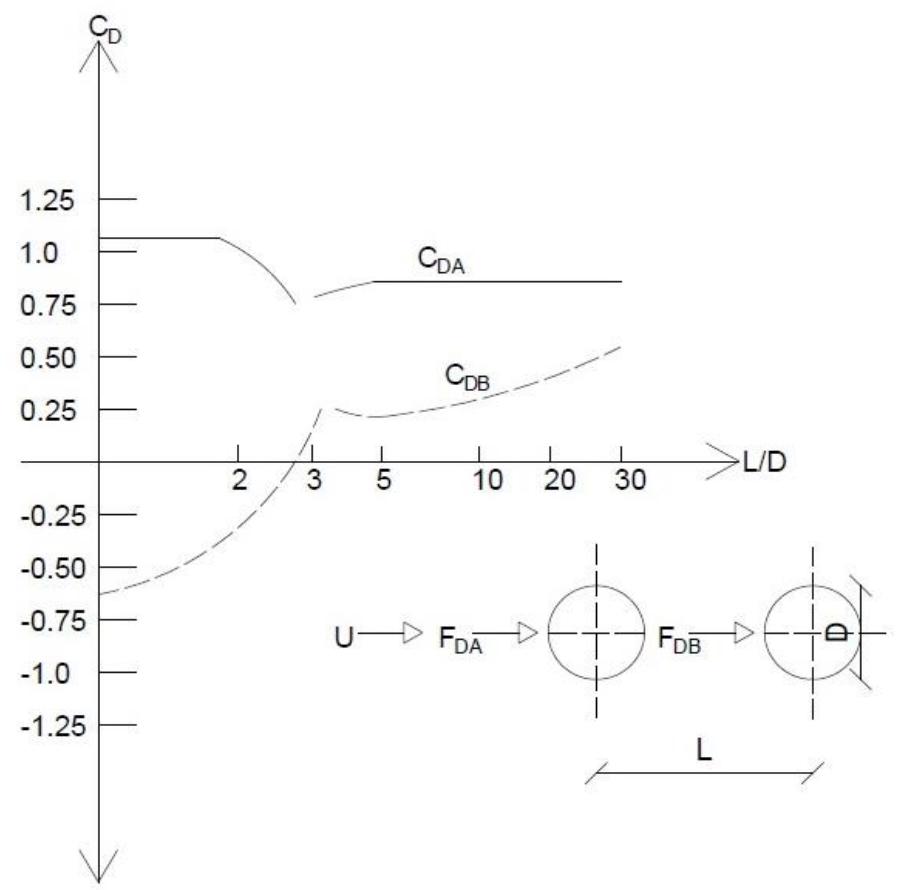

Figure 2 Hydrodynamic coefficients CDA and CDB [20]

\section{STATIC ANALYSIS OF THE STRUCTURE}

In the present paper a direct integration strategy has been used starting from the Runge-Kutta integration scheme of the differential equations of equilibrium. The equations have been written with reference to large deflections; moreover, axial deformation has been neglected and ovalization and warping have been supposed to be uninfluential with respect to flexural behaviour.

The actual structural scheme is depicted in the figure 3, the structural scheme has consisted of a simply supported beam. The end point constraints have been specified as hinged $(\mathrm{O})$ and supported $(\mathrm{P})$; the beam is subjected to uniform transversal load FD and axial pull force $\mathrm{H}$ exerted by the laying boat. 


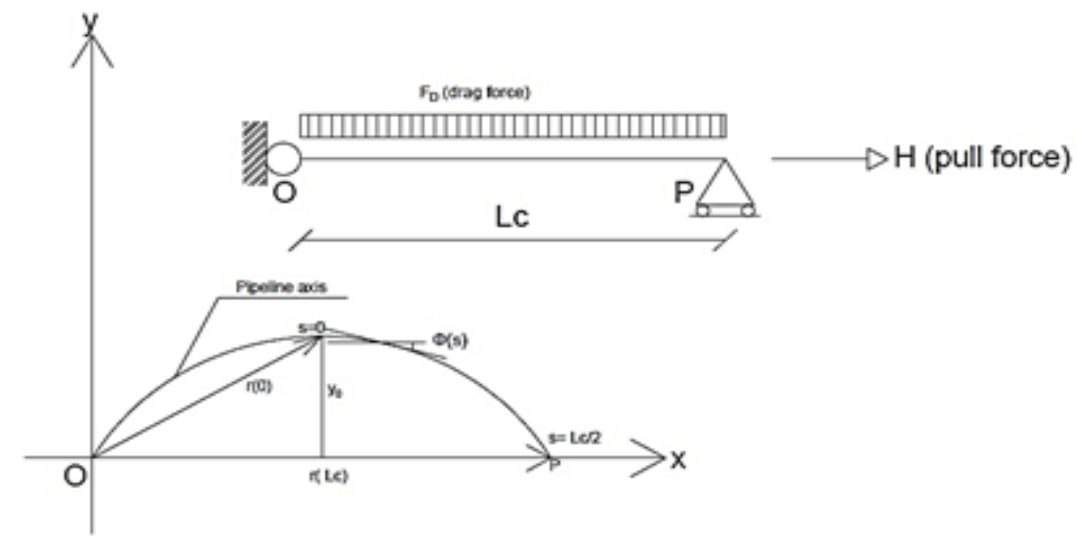

Figure 3 Static structural scheme

The equations have been written under the hypotheses that the pipeline forms a plain system where the deformed and undeformed structure belong to the same plain so did the applied loads. In the following, the axial deformation of the pipe has been neglected since for the ordinary dimensions the flexural displacements are of one order of magnitude greater than the axial ones.

Let us consider the orthogonal Cartesian frame $(\mathrm{O}, \mathrm{x}, \mathrm{y})$ as in figure 3 , the deformed configuration is identified by the position vector $\mathrm{r}(\mathrm{s})$ which is related to the curvilinear abscissa $\mathrm{s}$ through the relation $\mathrm{ds}=|\mathrm{dr}|$. The vector $\mathrm{r}$ is decomposed into the unknown scalar components:

$$
\begin{aligned}
& r_{x}=f_{1}(s) \\
& r_{y}=f_{2}(s)
\end{aligned}
$$

In the following it is useful to introduce the pipeline axis slope $\varphi(s)$ that represents the angle that the axis of the beam forms with the line passing through the two points of suspension that is the $\mathrm{x}$ axis of the reference frame.

The curvature of the structure is defined by the variation $\varphi^{\prime}(s)$ with respect to $s$ of the angle $\varphi(s)$.

The equilibrium equations have been written with reference to figure. 4 where the bending moment $\mathrm{M}$, the axial force $\mathrm{H}$ and the shear force $\mathrm{V}$ have been represented.

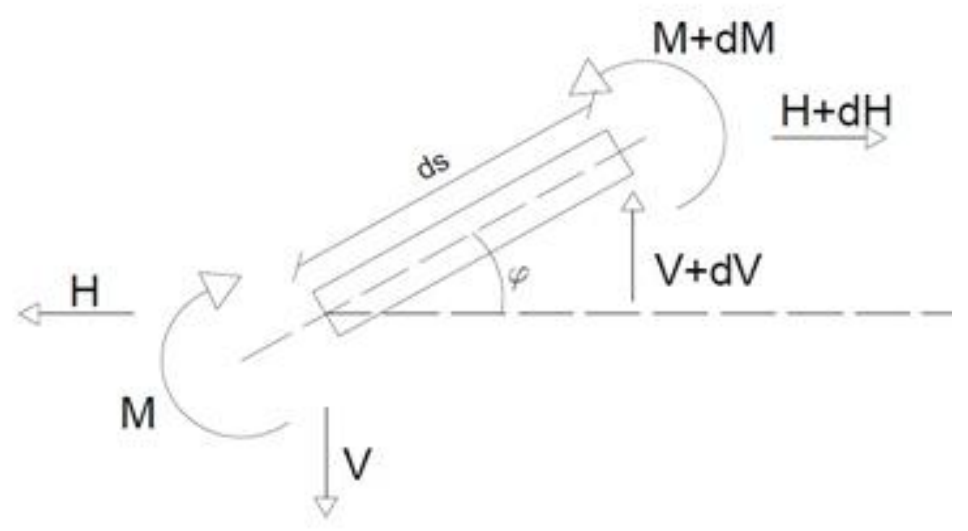

Figure 4 Stresses and strains on the "ds" length element of the structure 


$$
\left\{\begin{array}{c}
\frac{d M}{d s}-H \sin \varphi(\mathrm{s})+V \cos \varphi(\mathrm{s})=0 \\
\frac{d V}{d s}-F_{D}=0
\end{array}\right.
$$

Under the Bernoulli's classical hypothesis, the constitutive law of the bending beam is linear in the curvature, so that:

$$
M=E I \varphi^{\prime}(\mathrm{s})
$$

where $E$ is the Young modulus of the material constituting the beam; in the case of heterogeneous material, composite, layered and so on, homogenized modulus should be used. Moreover, $\mathrm{I}$ is the areal moment of inertia of the cross section and $\mathrm{M}$ is the bending moment acting on the section at the abscissa $\mathrm{z}$

The second of (3) has been solved directly then replaced in the first one. Furthermore, the equation (4) has been derived with respect to $s$ and substituted into the eq. (3).

$$
\left\{\begin{array}{c}
E I \varphi^{\prime \prime}(s)-H \sin \varphi(\mathrm{s})+V \cos \varphi(\mathrm{s})=0 \\
\mathrm{~V}=V_{0}+\int_{0}^{s} F_{D}(\lambda) d \lambda
\end{array}\right.
$$

The equations (5) should be completed by considering the suitable boundary conditions.

Due to the symmetry of the structure, only one half of the pipeline is solved by assuming that at the symmetry point was the curvilinear abscissa s origin and that the slope and the shear vanish (fig. 3):

$$
\left\{\begin{array}{l}
M(s=0)=\mathrm{c} \\
\mathrm{V}(\mathrm{s}=0)=0 \\
\varphi(s=0)=0
\end{array}\right.
$$

The conditions (6), contain the undefined parameter $\mathrm{c}$ representing the bending moment in the middle section of the pipeline.

The solution of (6) with the (7) could be introduced inside a numerical procedure whose steps have been described next. At this point a fixed arbitrarily parameter c, as previously introduced, has been calculated through an iterations cycle by means of step by step integration and solving the first of (5).

With the knowledge of $\varphi(s)$ function, it has been possible to calculate the bending moment from the relation (4) until:

$$
M\left(L_{C}\right)=0+\varepsilon
$$

With $\varepsilon$ as the pre-fixed system tolerance.

Then, the positioning vector $\mathrm{r}(\mathrm{s})$ has been calculated through the following equations:

$$
\begin{gathered}
r_{x}=\int_{0}^{s} \sin \varphi(\lambda) d \lambda \\
r_{y}=y_{0}+\int_{0}^{s} \cos \varphi(\lambda) d \lambda
\end{gathered}
$$

Where y0 represents the displacement at the middle side of the pipelines; in fact, at the suspension point $\left(s=\frac{L_{C}}{2}\right)$ :

$$
r_{y}\left(\frac{L_{C}}{2}\right)=y_{0}+\int_{0}^{\frac{L_{C}}{2}} \cos \varphi(\mathrm{s}) d \lambda
$$

Where:

$$
y_{0}=-\int_{0}^{\frac{L_{C}}{2}} \cos (\lambda) d \lambda=r_{y}(0)
$$

The whole procedure has been automatized using a routine program in "Mathematica ${ }^{\circledR}$ " (Wolfram 2019). 


\section{RESULTS}

In the present section two pipelines have been analyzed. They consist in coupled PRFV pipelines system with a diameter $\mathrm{D}=800 \mathrm{~mm}$ and $\mathrm{D}=1200 \mathrm{~mm}$ respectively. The commercial pipe wall thickness are $12 \mathrm{~mm}$ and $20 \mathrm{~mm}$, moreover the pipeline length has been $\mathrm{LC}=400 \mathrm{~m}$ in the both cases previously described.

The distance between pipes $\mathrm{L}$ has been assumed to be variable between $2 \mathrm{~m}$ and $4 \mathrm{~m}$ while the longitudinal distance 1 between two collars has been fixed at $10 \mathrm{~m}$.

Assuming a uniform current of speed $\mathrm{U}=0.10 \mathrm{~m} / \mathrm{s}$, the values of $F_{D}=F_{D A}+F_{D B}$ have been calculated by using (1) and the diagram in fig. 2 when the L/D ratio varied (see Tab.1 and fig.5).

Table 1 Hydrodynamic force subjected to variable diameter and pipelines distance

\begin{tabular}{|c|c|c|c|c|c|}
\hline $\mathrm{D}=800 \mathrm{~mm}$ & $\mathrm{~L}=2 \mathrm{~m}$ & $\mathrm{~L}=2,5 \mathrm{~m}$ & $\mathrm{~L}=3 \mathrm{~m}$ & $\mathrm{~L}=3,5 \mathrm{~m}$ & $\mathrm{~L}=4 \mathrm{~m}$ \\
\hline $\mathrm{L} / \mathrm{D}$ & 2,5 & 3,12 & 3,75 & 4,37 & 5 \\
\hline FD & 28,92 & 38,67 & 38,98 & 38,28 & 38,58 \\
\hline \hline $\mathrm{D}=1200 \mathrm{~mm}$ & $\mathrm{~L}=2 \mathrm{~m}$ & $\mathrm{~L}=2,5 \mathrm{~m}$ & $\mathrm{~L}=3 \mathrm{~m}$ & $\mathrm{~L}=3,5 \mathrm{~m}$ & $\mathrm{~L}=4 \mathrm{~m}$ \\
\hline $\mathrm{L} / \mathrm{D}$ & 1,66 & 2,08 & 2,5 & 2,91 & 3,33 \\
\hline FD & 35,5 & 39,4 & 43,38 & 47,44 & 58,17 \\
\hline
\end{tabular}

Moreover, assuming a value of the elastic modulus $E=20000 \mathrm{~N} / \mathrm{mm}^{\wedge} 2$ and calculated the moment of inertia I of the section, the deformed $\varphi(\mathrm{s})$ value has been calculated for each case through the (5), numerically as described above.

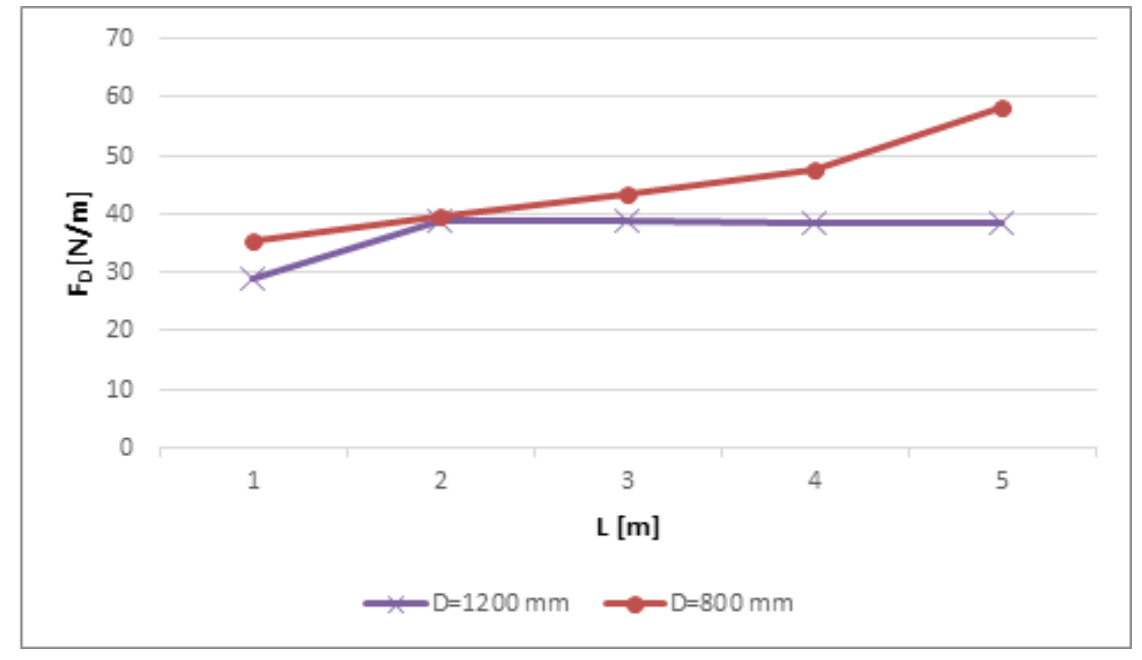

Figure 5 Hydrodynamic force FD

Parametric curves $\left[r_{x}(s), r_{y}(s)\right]$ for values of $s>0$ have been reported and calculated in fig. $6 \mathrm{a}$ and fig. $7 \mathrm{a}$ with the variation of the distance $\mathrm{L}$ between the pipelines and for a value of the pulling force equal to $\mathrm{H}=4000 \mathrm{~N}$. 
Non-Linear Strain Analysis of Coupled Sub-Marine Pipelines During the Launch Phase
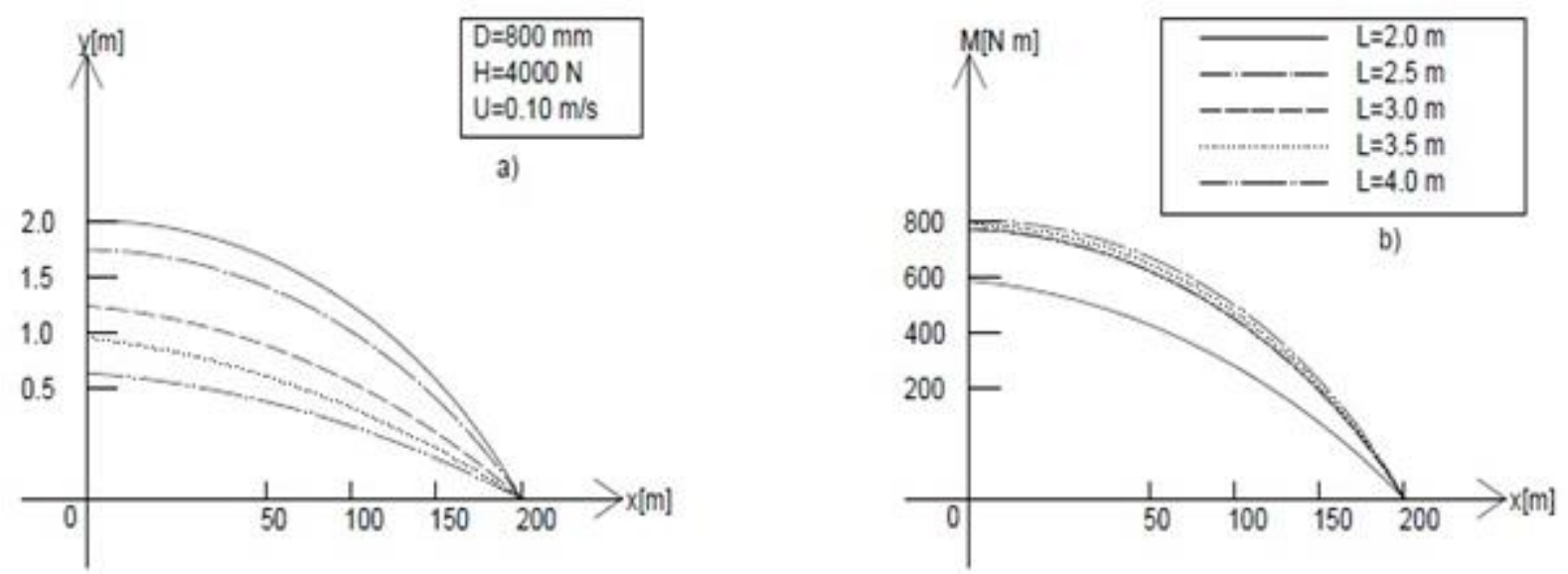

Figure 6 Horizontal pipelines displacements a) - Bending moments b) ( $D=800 \mathrm{~mm})$

Through fig. $6 \mathrm{~b}$ and $7 \mathrm{~b}$, for each scheme, has been reported the relative bending moment diagrams $M(x)$.
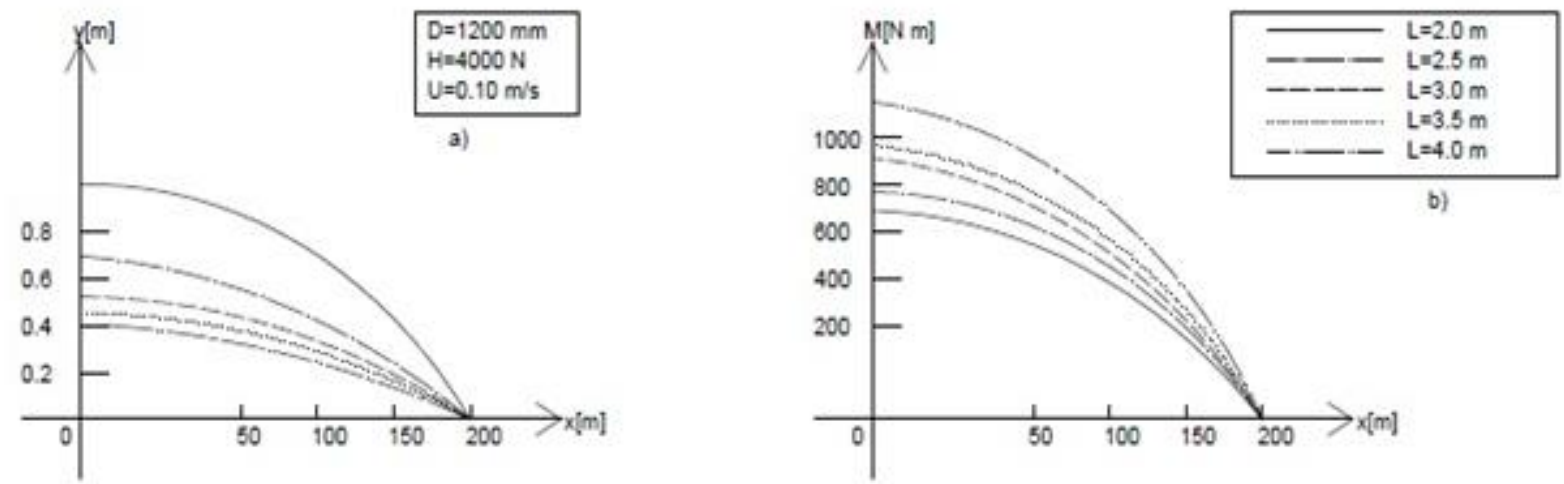

Figure 7 Horizontal pipelines displacements a) - Bending moments b) (D=1200 mm)

\subsection{Results Discussion}

From the examination of results, has emerged that for $\mathrm{H}=2000,4000,6000,8000,10000 \mathrm{~N}$, there were no influences of this parameter on the structure deformation, highlighting the negligible nature of the effects of the second order.
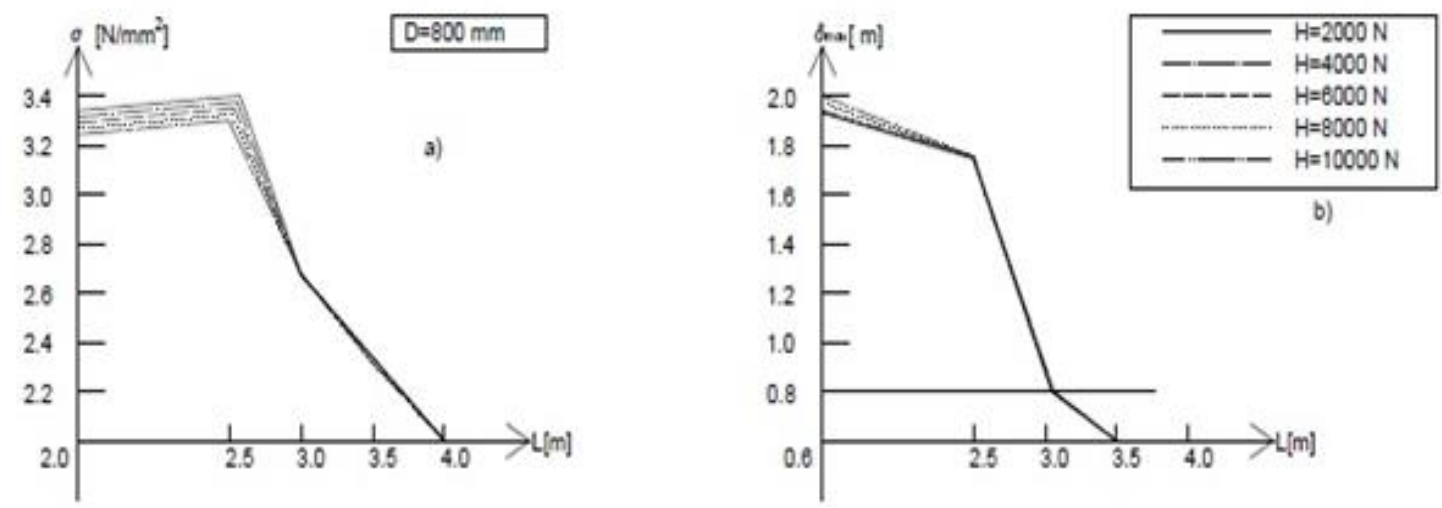

Figure 8 Maximum stresses a) - Maximum displacements b) ( $\mathrm{D}=800 \mathrm{~mm})$ 
Analyzing the diagrams in figs. $6 \mathrm{a}-\mathrm{b}$ relative to $\mathrm{D}=800 \mathrm{~mm}$, the deformed structures have values of the maximum horizontal displacement, $y(x)=\delta_{\max }$, varying between $0.7 \mathrm{~m}$ and 2 $\mathrm{m}$ as the distance $\mathrm{L}$ considered decreases. Moreover, for $\mathrm{L}$ value about $2.5 \mathrm{~m}$, the bending moment resulted independent from the distances between the two coupled pipelines since for L/D >3, the hydrodynamic load is Figure 9 Maximum stresses a) - Maximum displacements b) $(\mathrm{D}=800 \mathrm{~mm})$ constant (see fig.2) and the bending moment is independent from the structural deformation, geometry of the section and pull force. Vice versa, for $\mathrm{L}<2.5 \mathrm{~m}$, the deformation effect involves a decrease of the maximum bending moment for the fact that is associated to the negative values of FDB (fig.2).
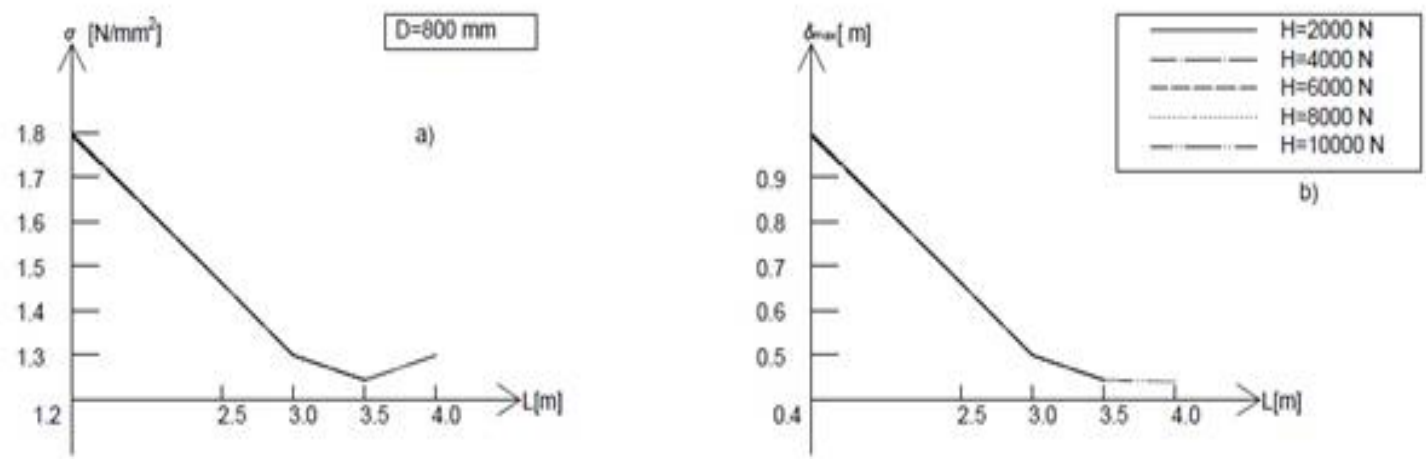

Figure 9 Maximum stresses a) - Maximum displacements b) (D=1200 mm)

As concerns the diameter $\mathrm{D}=1200 \mathrm{~m}$, from fig. $7 \mathrm{a}-\mathrm{b}$ has been noted that the deformed structures have a variability of the maximum horizontal displacement. $\delta_{\max }$, between $0.4 \mathrm{~m}$ and $0.9 \mathrm{~m}$ as the distance $\mathrm{L}$ considered decreases.
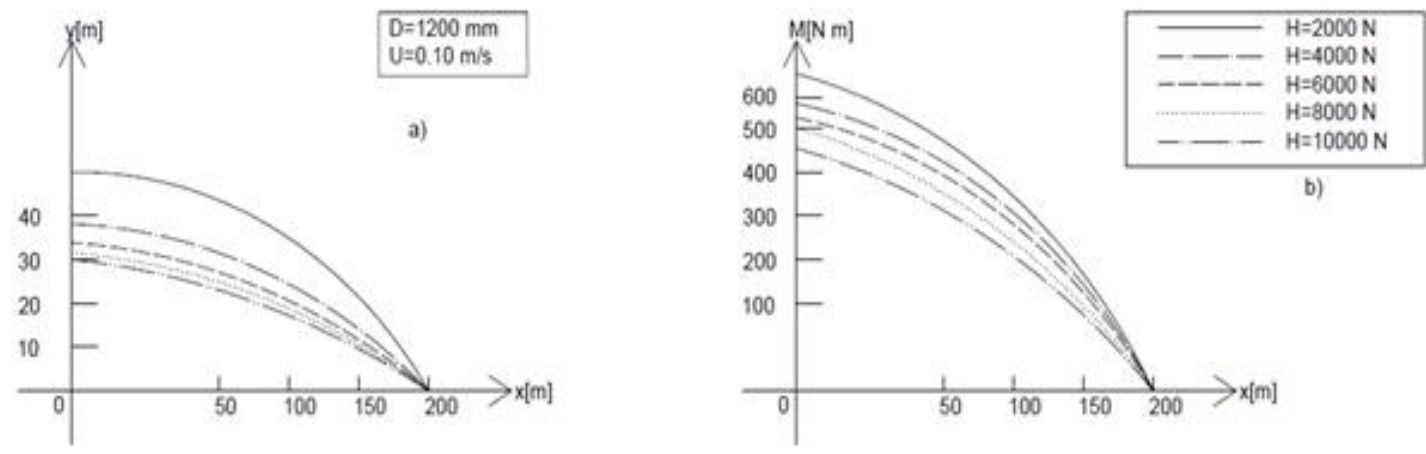

Figure 10 Maximum displacements a) - Bending moments b) For single pipeline ( $D=1200 \mathrm{~mm}$ )

As well, the bending moment is always decreased with L compared to the previous case, because for $\mathrm{L} / \mathrm{D}<3$, the transversal loads FD never results constant (see Tab.1).

The trend of the stress $\sigma$ and of the maximum horizontal displacements $\delta_{\max }$ with the distance $\mathrm{L}$, for prefixed values of the pulling force $\mathrm{H}$ is shown in fig. $8 \mathrm{a}-\mathrm{b}$, for $\mathrm{D}=800 \mathrm{~mm}$ and in fig.9a-b, for $\mathrm{D}=1200 \mathrm{~mm}$. It is possible to note that in both cases, the values of $\delta_{\max }$ decrease quickly as L increases and are independent from the parameter $\mathrm{H}$. The $\sigma$ stresses, for $\mathrm{D}=800 \mathrm{~mm}$, are constant up to $\mathrm{L}=2.5 \mathrm{~m}$, and for higher values, they decrease with this parameter. Moreover, due to the high displacements, as the distance L decreases, $\sigma$ decreases with the force $\mathrm{H}$. In the case of $\mathrm{D}=1200 \mathrm{~mm}$, the maximum stresses are always decreasing with $\mathrm{L}$ and the parameter $\mathrm{H}$ does not influence them.

Finally, In order to highlight the advantages of the method of launching proposed in the paper, in fig.10a-b, it has been reported the values of $y(x)$ of the deformed and the 
corresponding values of the bending moment $\mathrm{M}(\mathrm{x})$ with a variable pulling force $\mathrm{H}$, in respect to the case of a single pipe of diameter $\mathrm{D}=1200 \mathrm{~mm}$ subjected to the action of a sea current of speed $\mathrm{U}=0.10 \mathrm{~m} / \mathrm{s}$.

It has been seen that the values of $\delta_{\max }$ are between 30 and $40 \mathrm{~m}$ at decreasing $\mathrm{H}$ and are on average equal to 40-70 times the maximum displacements that occur in the case of coupled pipelines of equal diameter (see fig.7a).

Vice versa, the bending moments, are about equal to half of those corresponding to the combined structure (see fig. $7 b$ ).

\section{CONCLUSIONS}

The operations of installing two or more submarine pipelines in parallel can be optimized, if by using the technique of shooting on the bottom, the simultaneous launch of the two pipelines is made by coupling them through a system of collars connected by a spacer element.

The advantage of the solution proposed in the paper is represented by the shorter time (therefore the lower risk) required for the launch compared to the case of installation for single pipelines. Moreover, in the presence of a U current during the launch phase, the system of two coupled pipes present a higher transversal stiffness, making this solution subjected to lower deformations.

This last aspect is particularly important in the case of plastic pipes, in fact, the deformed structure has been analyzed considering it schematically as an inflected beam hinged at the end to the ground and supported in the offshore one.

About hydrodynamic loads FD due to sea flow, reference has been done to Morison's semi-empirical relationship using for the estimation of hydrodynamic coefficients the experimental results shown in fig. 2 .

The equation of the deformed, however, has been obtained from the equations of static equilibrium, starting from the curvature expressed by the differential equation of the system (5), linked only to the parameter $\varphi(s)$. The resolution about the equations (6) using a numerical model allowed to determine the structure deformed to varying FD, D, L and EI.

In the example proposed inside the paper is possible to highlight:

The pull force $\mathrm{H}$ has not been influenced the structure deformed.

If the drag force FD remains constant with the increasing of $\mathrm{L}$, bending moments are not affected by such loads; Vice versa, when the FD drag force does not remain constant, the bending moments decrease to the increasing of length $\mathrm{L}$.

The maximum stresses, $\delta_{\max }$, always result decreasing with $\mathrm{L}$, and $\mathrm{H}$ never influences it.

In the case of single pipeline, the maximum strains have been resulted, for $D=1200 \mathrm{~mm}$ and $U=0.10 \mathrm{~m} / \mathrm{s}$, about 40-70 times higher than the same in case of coupled pipelines of equal diameter; bending moments, instead, resulted to values about a half in respect to the ones of a coupled pipelines scheme.

\section{REFERENCES}

[1] O. B. M. J. J. S. S. Morison J.R., The forces exerted by surface waves on piles, Petroleum Transactions, vol. 189, 1950.

[2] W. H., Dynamik Offshoretechnisher linientragwerke am beispiel der pipelineverlegung, Berlin: Tesi di dottorato, Technishen Universitat, 1990.

[3] W. H. a. R. T. Clauss G.F., Offshore Pipe Laying Operation-Interaction of vessel motions and pipeline dynamic stresses, Applied Ocean Research, vol. 14, n. 3, pp. 175-186, 1990. 
[4] W. H. a. S. A. Clauus G.F., Non-linear static and dynamic analysys of marine pipelines during laying, Ship Technology Research, vol. 38, n. Berlino, pp. 76-107, 1991.

[5] G. F. Minutolo V., Analisi dell'ovalizzazione di condotte circolari in regime di spostamenti finiti, in Atti giornate di studio in ricordo di Mario Ippolito, Ass. Idrotecnica Italiana, Napoli, 1996.

[6] M. V. Guarracino F., A Refined analitical analysis of submerged pipelines at seabed lying, Applied ocean research, vol. 21, n. 6, 1999.

[7] N. A.H., Perturbation methods, New York: Wiley, 1973.

[8] K. I., Higher order approximations in stress analysis of submarine pipelines, Journal of Energy Researches Technology, vol. 4, pp. 190-196, 1980.

[9] C. Y. Zhu D.S., Optimization of Bouyancy of an Articulated Stinger on Submerged Pipelines Laid with a Barge, Ocean Engineering, vol. 24, n. 4, pp. 301-311, 1997.

[10] Numerical analysis on pipeline laying for intake deep ocean water |Request PDF, [Online]. Available:

https://www.researchgate.net/publication/292847028_Numerical_analysis_on_pipeline_la ying_for_intake_deep_ocean_water.

[11] M. J. Bianco, A. K. Habtemariam, C. Könke, F. Tartaglione e V. Zabel, Analysis of support coupling GBT (Generalized Beam Theory) applied in pipeline systems, ThinWalled Structures, vol. 146, 112020.

[12] C. C. Jacinto Portela, A. Jarek E L. A. De Lacerda, Coupling of the Boundary Element Method with a Hybrid Method for Inverse Stress Analysis of Pipelines, in Boundary Elements and other Mesh Reduction Methods XLII, 2019.

[13] N. Wang, Q. Xu e Y. Zhang, Mathematical modelling and solution of pipeline laying problem, International Journal of Simulation and Process Modelling, vol. 7, n. 1-2, pp. 16-22, 72012.

[14] H. Wei, Y. Jiang, G. Xing e D. Zhang, Simulation of subsea pipeline laying process in deep water, in ICPTT 2014 - Proceedings of the 2014 International Conference on Pipelines and Trenchless Technology, 2014.

[15] B. G.K., An introduction to flui dynamics, Cambridge University Press, 1967.

[16] K. R. Bober W., Fluid mechanics, Jhon Wiley and Sons, 1980.

[17] C. S.K., Hydrodynamics of offshore structures, Southampton Boston: Computational Mechanics Publications, 1987.

[18] C. P. Di Natale M., Azioni idrodinamiche indotte dal moto ondoso sulle condotte sottomarine, Offshore and Marine Engineering, vol. 2, 1988.

[19] S. T., In-line and transvers forces on cylinder near a wall in oscillatory flow at high Reynolds numers, in Proceedings 9th offshore technology conference, Houston, 1977.

[20] I. M. Sarpkaia T., Mechanics of wave forces on offshore structures, New York: Van Nostrand Reynolds, 1981.

[21] Z. M.M., Review of flow interference between two circular cylinder in various arrangements, Journal of fluids engineering, vol. 99, n. 4, 1977.

[22] W. S., The Mathematica Book, Cambridge: Wolfram Media Cambridge University Press, 2019. 